\title{
VOR WORT
}

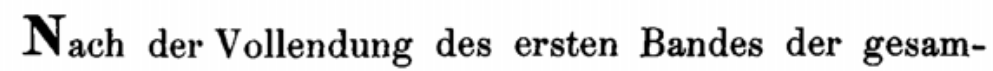
melten Abhandlungen war Gerhard auf den Gedanken gekommen, ob es nicht zweckmässig sei, die Fortsetzung auf die eigentlich archäologischen Abhandlungen zu beschränken, da es für ihn ein Hauptaugenmerk gewesen war, die auf den dazu gehörigen Tafeln zusammengestellten Monumente den Archäologen bequemer zugänglich zu machen. Diesen Vorsatz habe ich bei der Redaction dieses Bandes zur Ausführung gebracht und zwei Winckelmannsprogramme hinzugefügt, deren Kupfertafeln nicht, wie es bei den anderen der Fall ist, anderweitig wieder publicirt worden sind. Ausgeschlossen blieben die vorläufigen Publicationen etruskischer Spiegel, welche nachher in das grosse Hauptwerk aufgenommen worden sind.

Bonn Juli 1868.

Otto Jahn. 
